\title{
AVALIAÇÃO DA INCIDÊNCIA DE BRUSONE EM ARROZ (Oryza sativa L.) DE TERRAS ALTAS SOB CULTIVO COM DIFERENTES DOSAGENS DE AGROSILÍCIO E ROTAÇÃO DE CULTURA COM SOJA (Glycine max (L.) Merrill) EM SISTEMA DE PLANTIO DIRETO
}

\author{
Neidelâne de Alencar Sobrinho ${ }^{1}$; Gisellya de Araújo Cruz ${ }^{1}$; Gustavo de Andrade \\ Bezerra $^{1}$; Ivaneide de Oliveira Nascimento ${ }^{2}$; Gisele Barata da Silva ${ }^{3}$; Marta Cristina \\ Corsi de Filippi ${ }^{4}$.

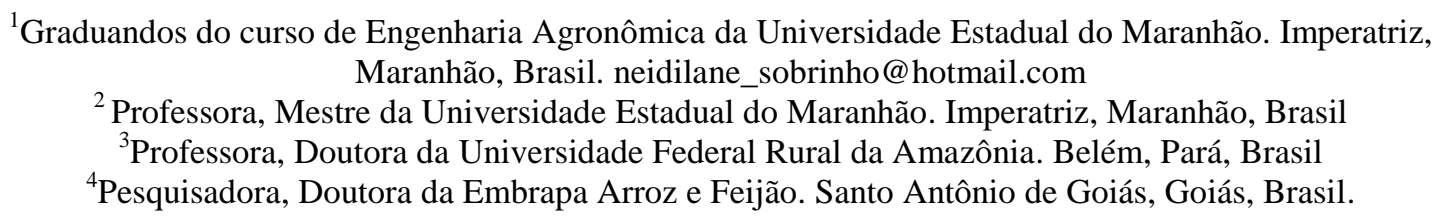

RESUMO: O Brasil é o oitavo produtor mundial de arroz. No Maranhão, o arroz é cultivado em consórcio com outras culturas, destacando-se o feijão e o milho, sendo pouco frequente o cultivo isolado. A cultura do arroz é afetada por diversos fatores, sendo as doenças fúngicas uma das principais responsáveis pela perda da produtividade. No entanto o agrosilício (silicato de cálcio, magnésio e silício) tem sido testado em diversos experimentos, pois o silício aumenta a resistência da planta. O presente trabalho objetivou analisar a resposta da planta ao agrosilício, considerando a incidência de doenças e estabelecer a dose mais eficiente de silicato de cálcio e magnésio para compor o manejo integrado de doenças do arroz, no estado do Maranhão. O experimento foi instalado nas dependências do Parque de Exposição de Imperatriz-MA, pertencente ao Sindicato Rural de Imperatriz, situado a BR 010, em uma área cultivada no ano anterior com soja (Glycine max (L.) Merrill). Em delineamento de blocos ao caso com parcelas subdivididas e quatro repetições, os cinco tratamentos são compostos pelas doses de silício $(0,1,2,4,8$ t/ha de silicato de cálcio e magnésio Agrosilício). De acordo com os dados das análises estatísticas não houve diferença significativa entre nenhuma das dosagens de silício aplicadas para o controle das doenças: brusone nas folhas, brusone nas panículas, sendo necessária a condução de novos experimentos para indicar-se a melhor dosagem de agrosilício a ser aplicada ao solo para redução das doenças do arroz.

Palavras-Chaves: Rizicultura, fungos e adubação silicatada.

\section{ASSESSING THE IMPACT OF RICE BLAST (Oryza sativa L.) LAND HIGH UNDER CULTIVATION WITH DIFFERENT STRENGTHS OF AGROSILÍCIO AND ROTATION OF CULTURE WITH SOYBEAN (Glycine max (L.) Merrill) IN SYSTEM TILLAGE}

\begin{abstract}
Brazil is the eighth largest producer of rice. In Maranhão, rice is intercropped with other crops, especially beans and corn, with rare isolated cultivation. The rice crop is affected by several factors, fungal diseases are major responsible for the loss of productivity. However, the agrosilício (calcium silicate, magnesium and silicon) is being tested in several experiments, the silicon increases the resistance of the plant. This study aimed to analyze the response of the plant to agrosilício, considering the incidence of diseases and establish the
\end{abstract}


most efficient dose of calcium silicate and magnesium to compose the integrated management of rice diseases in the state of Maranhão. The experiment was installed in the premises of the Exhibition Park of Imperatriz-MA, belonging to the Rural Union Imperatriz, situated at BR 010, in a cultivated area in the previous year with soybean (Glycine max (L.) Merrill). In randomized block split plot with four replications, the five treatments are composed of the silicon doses $(0,1,2,4,8 \mathrm{t} /$ ha calcium silicate and magnesium - Agrosilício). According to the data of the statistical analysis there weren't no significant difference between any dose of silicon applied to the control of the diseases: leaf blast, panicle blast, being necessary to conduct further experiments to indicate the best agrosilício dosage to be applied to the soil to reduce rice diseases.

Key Words: Rice culture, fungi and silicon fertilization.

\section{INTRODUÇÃO}

O Brasil é o oitavo produtor mundial de arroz (Oriza sativa) sendo que no ano de 2005 foram cultivados aproximadamente quatro milhões de hectares, alcançando a produção de mais de 13 milhões de toneladas (IBGE, 2012). No Maranhão, o arroz é cultivado em consórcio com outras culturas, destacandose o feijão (Phaseolus vulgaris L.) e o milho (Zea mays L.), sendo pouco frequente o cultivo isolado (FERRAZ JÚNIOR, 2000), situação da agricultura de vazante.

No Maranhão a cultura do arroz é afetada por diversos fatores, as doenças fúngicas é uma das principais responsáveis pela perda da produtividade. Dentre as principais doenças destaca-se a brusone (Pyricularia grisea (Cooke) Sacc), mancha parda (Drechslera oryzae (Breda de Hann) Subr.\&Jain (sin. Bipolaris oryzae), mancha estreita (Cercospora janseana Miyek), escaldadura (Microdochium oryzae), queima das bainhas (Rhizoctonia oryzae Riker \& Gooch) e manchas dos grãos (Phoma sp., Drechslera oryzae, Curvularia lunata, Nigroppora oryzae, Alternaria sp., Fusarium sp.) (DALLAGNOL et al., 2006); sendo a brusone a principal doença de ocorrência no arroz por atacar a planta em todos os estágios do seu desenvolvimento.

No entanto, pesquisas realizadas em solos orgânicos (Histossolos) no sul da Flórida, nos Estados Unidos, demonstraram que a fertilização do arroz com silicato de cálcio reduziu a incidência de brusone de 17 a $31 \%$ e da helmintosporiose de 15 a 32\% (DATNOFF et al., 1991, 1992).

Assim, no sentido de buscar uma agricultura mais sustentável diminuindo o uso de fungicidas, o presente trabalho objetivou analisar a resposta da planta ao agrosilício, considerando a incidência de 
brusone e estabelecer a dose mais eficiente de silicato de cálcio e magnésio para compor o manejo integrado de doenças do arroz, no estado do Maranhão.

\section{MATERIAL E MÉTODOS}

$\mathrm{O}$ experimento foi instalado em um solo do tipo Latossolo Vermelho Amarelo de textura argilosa em uma área localizado nas dependências do Parque de Exposição de Imperatriz-MA, pertencente ao Sindicato Rural de Imperatriz, situado a BR 010, em uma área cultivada no ano anterior com soja (Glycine max (L.) Merrill).

Foi utilizado o delineamento de blocos ao caso com parcelas subdivididas e quatro repetições, os cinco tratamentos são compostos pelas doses de silício $(0,1,2,4$, 8 t/ha de silicato de cálcio e magnésio Agrosilício.

A coleta de solo foi efetuada com trado, em cada uma das parcelas, em três pontos distintos, à profundidade de $20 \mathrm{~cm}$. Misturando-se as três amostras de um mesmo ponto, fez-se uma amostra composta, para cada parcela analisada.

De acordo com os resultados da análise de solo, a área apresenta baixo teor de matéria orgânica, característica de solo arenoso, baixa CTC total e efetiva, o $\mathrm{pH}$ do solo analisado varia de 4,9 a 6,2 , necessitando de uma correção para manter o padrão de qualidade.

A aplicação do calcário e agrosilício foram realizadas em dezembro/11. O Silicato de cálcio, magnésio e silício (agrosilício) foi aplicado nas quantidades de $0,1,2,4$ e 8 t/ha. O calcário foi aplicado na quantidade necessária de cálcio e magnésio para alcançar a maior dosagem do agrosilício. A parcela foi dividida em duas subparcelas, as quais uma recebeu uma nova aplicação, e a outra permaneceu com a adubação residual da soja.

Anteriormente ao plantio as sementes passaram por um procedimento de microbiolização com rizobactérias dos gêneros Pseudomonas sp. e Burlkoderia sp., que foram multiplicadas em meio de cultura 523 e levadas à estufa bacteriológica para crescimento por 48 horas. Nesse processo foram microbiolizadas $2,6 \mathrm{~kg}$ de sementes, as quais foram mergulhadas na suspensão bacteriana e levadas para mesa agitadora modelo CT-155T Cientec, permaneceram sob agitação por 24 horas antes do plantio.

O plantio foi conduzido em sistema de plantio direto, com parcelas de $3,50 \mathrm{~m} \mathrm{x}$ $12,00 \mathrm{~m}$. A parcela foi subdividida em quatro subparcelas, composta por dez linhas, em que cinco linhas eram compostas por sementes que não passaram por procedimento de microbiolização e 
cinco linhas com sementes microbiolizadas, uma subparcela com efeito residual do silicato de cálcio e magnésio, calcário aplicado no ano anterior e a outra com nova aplicação de silicato de cálcio e magnésio, calcário.

Antes do plantio foram realizadas todas as correções de acordo com a análise de solo, uma vez que para a aplicação do NPK utilizou-se a formulação 5-30-15, e em cada parcela foram aplicadas doses equivalentes 1 (um) $\mathrm{kg}$ de adubo. A adubação e o plantio foram realizados em sulcos com profundidade de $2-3 \mathrm{~cm}$.

As análises de incidências de brusone nas folhas aconteceram aos 48 dias após o plantio. Cada parcela foi subdividida em quatro subparcelas de acordo com o esquema experimental do plantio, observou-se 10 folhas escolhidas ao acaso de cada subparcela e as manchas foram avaliadas de acordo com o grau de severidade utilizando a escala de notas de 10 graus de Nothegan. Realizaram-se quatro leituras independentes com intervalos de 2 a 3 dias.

As análises de brusone nas panículas foram realizadas aos 93 dias após o plantio, as leituras foram repetidas cinco vezes em cada uma das parcelas com intervalos de dois a três dias. Para as análises, observou-se a queda de grãos em 10 panículas escolhidas casualmente, através desta característica indagou-se a severidade da doença, que foi avaliada por meio da escala de notas de cinco graus.

Os dados de ambas as análises foram anotados no caderno de campo para análises estatísticas utilizando o aplicativo assistat 7.6.

Coletaram-se algumas amostras, que foram acondicionadas em sacos plásticos e posteriormente levadas para o Laboratório de Fitopatologia, Microbiologia e Alimentos (LFMA) da Universidade Estadual do Maranhão (UEMA), Centro de Estudos Superiores de Imperatriz (CESI), para procedimentos de isolamento de fungo nas folhas e panículas.

\section{RESULTADOS E DISCUSSÕES}

De acordo com os dados das análises estatísticas não houve diferença significativa entre nenhuma das dosagens de silício aplicadas para o controle das doenças: brusone nas folhas, brusone nas panículas (Tabela 1). Dentre os fatores que podem ter influenciado a não diminuição da incidência de brusone no arroz em reposta a aplicação do agrosilício, pode-se citar a alta precipitação pluviométrica no período de condução do experimento e ataque de pragas no plantio. Por conseguinte houve perda de parcelas, e nas análises estatísticas os coeficientes de variação ficaram altos, sendo necessária a 
condução de novo experimento para indicar a melhor dosagem de agrosilício a ser aplicada ao solo. Entretanto, de modo geral vale ressaltar que as menores médias de incidência das doenças estão nos tratamentos com as menores dosagens de agrosilício. Os resultados desta pesquisa coincidem com os obtidos no trabalho de (SANTOS et al., 2003) que relata que nenhuma das fontes de $\mathrm{Si}$ aplicadas diferenciou da testemunha para o controle da mancha parda na folha bandeira, incidência de brusone nas panículas e severidade de mancha dos grãos.

Tabela 1. Avaliação da incidência de brusone no arroz (Oryza sativa L.) cultivado sob diferentes dosagens de agrosilício, Imperatriz-MA, 2011/2012.

\begin{tabular}{lcccc}
\hline Tratamentos & \multicolumn{2}{c}{$\begin{array}{c}\text { Incidência de Brusone Foliar } \\
\left(\mathrm{n}^{\circ} \text { de folhas infestadas) }\right.\end{array}$} & \multicolumn{2}{c}{$\begin{array}{c}\text { Incidência de Brusone nas Panículas } \\
\left(\mathrm{n}^{\circ} \text { de Panículas infestadas) }\right.\end{array}$} \\
& Adubação Nova & Adubação Residual & Adubação Nova & Adubação Residual \\
\hline $\mathrm{T} 1=0 \mathrm{t} / \mathrm{ha}$ & $21,13 \mathrm{a}$ & $33,63 \mathrm{a}$ & $6,43 \mathrm{a}$ & $3,31 \mathrm{a}$ \\
$\mathrm{T} 2=1 \mathrm{t} / \mathrm{ha}$ & $17,04 \mathrm{a}$ & $12,03 \mathrm{a}$ & $2,93 \mathrm{a}$ & $6,28 \mathrm{a}$ \\
$\mathrm{T} 3=2 \mathrm{t} / \mathrm{ha}$ & $18,50 \mathrm{a}$ & $19,50 \mathrm{a}$ & $7,44 \mathrm{a}$ & $2,91 \mathrm{a}$ \\
$\mathrm{T} 4=4 \mathrm{t} / \mathrm{ha}$ & $21,25 \mathrm{a}$ & $25,50 \mathrm{a}$ & $3,05 \mathrm{a}$ & $4,44 \mathrm{a}$ \\
$\mathrm{T} 5=8 \mathrm{t} / \mathrm{ha}$ & $27,51 \mathrm{a}$ & $18,14 \mathrm{a}$ & $5,06 \mathrm{a}$ & $6,53 \mathrm{a}$ \\
\hline C.V.(\%) & & 37,12 & & 123,61 \\
\hline
\end{tabular}

É importante ressaltar que trabalhos envolvendo silício no controle de doenças fúngicas estão sendo desenvolvidos recentemente, não sendo encontrado na literatura trabalhos deste tipo realizado na região. Todavia pesquisas realizadas em solos orgânicos no Sul da Flórida demonstraram que a fertilização com $\mathrm{Si}$ reduziu a incidência de brusone de $17 \%$ a $31 \%$ e a mancha parda de $15 \%$ a $32 \%$ em relação ao tratamento que não recebeu silício (DATNOFF et al., 1990, 1991). O $\mathrm{Si}$ absorvido pela planta depositado principalmente na parede celular, abaixo da cutícula, aumenta a rigidez da célula (ADATIA; BESFORD, 1986), dificultando a penetração dos patógenos.

\section{CONCLUSÃO}

Nas condições em que foi realizado este trabalho as dosagens de agrosilício não influenciaram a diminuição da brusone. Para a indicação da melhor dosagem de agrosilício seria necessário novo experimento, pois a aplicação do silicato de cálcio, magnésio e silício, promove resistência na planta dificultando a penetração dos patógenos. Dessa forma o 
uso de fungicidas, que hoje se encontra como um dos meios mais utilizados para o controle das doenças fúngicas será diminuído, e o uso do silício contribuirá para uma agricultura mais sustentável.

\section{REFERÊNCIAS}

ADATIA, M. H.; BESFORD, R. T. The effects of silicicon on cucumber plants grow in recirculating nutrient solution. Annual Botany, v. 58, p. 343-351, 1986.

DALLAGNOL， L. J.; NAVARINI， L.; BALARDIN, R. S.; GOSENHEIMER, A.; MAFFINI, A. A. Damage of leaf diseases in irrigated rice crop and efficiency of fungicides control. R. Bras. Agrociência, Pelotas, v. 12, n. 3, p. 313-318, jul-set, 2006.

DATNOFF, L. E.; RAID, R.N.; SNYDER, G.H.; JONES, D. B. Effect of calcium silicate on blast and brown spot intensities and yields of rice. Plant Disease, St. Paul, v. 75, p. 729-732, 1991.

DATNOFF, L. E.; RAID, R. N.; SNYDER, G. H., JONES, D. B. Evaluation of calcium silicate slag and nitrogen on brown spot, neck rot, and sheath blight development on rice. Biological and Cultural Tests for Control of Plant Diseases, St. Paul, v. 5, p. 65, 1990.

EPSTEIN, E. The anomaly of silicon in plant biology. Proceedings of National
Academy of Sciences of the United States of America, Washington, v. 91, n. 1, p.11-17, 1994.

FERRAZ JÚNIOR, A. S. de L. Arroz de sequeiro em aléias de leguminosas em solos de baixa fertilidade natural. 2000 . 196 f. Tese (Doutorado em Ciência do Solo) Universidade Federal Rural do Rio de Janeiro, Seropédica, 2000.

INSTITUTO BRASILEIRO DE GEOGRAFIA E ESTATÍSTICA. Levantamento sistemático da produção agrícola - LSPA: pesquisa mensal de previsão e acompanhamento da safra agrícola no ano civil. Rio de Janeiro, 2006. SANTOS, G. R.; KORNDORFER, E. H.; PRABHU A. S. Silicon efficiency combined wtth nitrogen and seed treatment on disease control of paddy brice. Biosci. J., Uberlândia, v. 19, n. 3, p. 43-49, Sept/Dec.2003. 